\title{
Facilities Economics in Australia
}

Author: Bernard Williams with Brian Purdey

Published by International Facilities \& Property Information Ltd, forthcoming

Reviewed by Professor Craig Langston, Deakin University

This major manuscript has its roots in a UK publication by Bernard Williams Associates printed initially in 1994. The new Australian edition reflects significant change over its predecessors and enables what some might refer to as a landmark text to be made more relevant to the Australian marketplace. There is also an EU version (unsighted). The manuscript is presented for review as a penultimate draft, in two volumes. Unfortunately there were numerous known editorial issues still to be resolved, and it is expected that these will be rectified before final publication occurs.

Facilities Economics in Australia is edited by Bernard Williams with significant contributions from Brian Purdey (as Editorial Consultant) and Geoff Parsons (as Managing Editor). The book acknowledges further specialist contributions from a number of Australian experts including Nick Birbara, Rozy Dorizas, Joe Galea, Kate Gunton, David Hope, Vince Hughes, Kim Jessop, Robert McCuaig and David Week.

The work is divided into eight parts. Part A deals with facilities and their management, and provides an overview of the FM discipline and the key aspects of practice. Part B looks at premises issues, including aspects of commercial real estate, space management, premises operating services, and fit-out and alterations. Part $C$ covers business support and staff support services, while Part D covers relocation and development. Part E represents a major rewrite on UK and presumably EU versions and concerns taxation impacts and legislation. Part F makes an important contribution concerning facility auditing and benchmarking performance. The remaining parts contain appendices and indexes.

Clearly, Facilities Economics in Australia is a significant piece of scholarship. It represents nearly 1000 pages of original content interspersed with numerous tables and figures that illustrate and expand on the text. Arguably this is the most comprehensive exploration of the economics of the built environment that exists, and it is of note to now have a version specific to the Australian context.

If I had to make one criticism, it would be the lack of a section on triple bottom line accounting and the evaluation of sustainability as part of the economic decision processes for facilities. Sustainable development is a hot topic in Australia and deserves more elaboration than that provided in this first edition.

Facilities Economics in Australia is highly recommended to everyone involved in facilities management and in particular to those specialist consultants that engage in financial appraisals, auditing and benchmarking. Although not mentioned in the preamble, previous additions of this text were accompanied by electronic resources (on CDRom) that gave further assistance and educational/training support. Perhaps this is work in progress.

The book will be available from Kodo Pacific Pty Ltd, Level 4, 81 York Street, Sydney, NSW, 2000 for $\$ 299$ plus $\$ 25$ p\&p. 